\title{
Silencing and Heterologous Expression of ppo-2 Indicate a Specific Function of a Single Polyphenol Oxidase Isoform in Resistance of Dandelion (Taraxacum officinale) Against Pseudomonas syringae pv. tomato
}

\author{
Carolin Richter, ${ }^{1}$ Mareike E. Dirks, ${ }^{1}$ Christian Schulze Gronover, ${ }^{2}$ Dirk Prüfer, ${ }^{1,2}$ and \\ Bruno M. Moerschbacher ${ }^{1}$ \\ ${ }^{1}$ Westphalian Wilhelms-University of Münster, Department of Plant Biology and Biotechnology, Hindenburgplatz 55, \\ 48143 Münster, Germany; ${ }^{2}$ Fraunhofer Institute for Molecular Biology and Applied Ecology (IME), Forckenbeckstrasse 6 , \\ 52074 Aachen, Germany
}

Submitted 1 April 2011. Accepted 17 October 2011.

\begin{abstract}
Dandelion (Taraxacum officinale) possesses an unusually high degree of disease resistance. As this plant exhibits high polyphenol oxidase (PPO) activity and PPO have been implicated in resistance against pests and pathogens, we analyzed the potential involvement of five PPO isoenzymes in the resistance of dandelion against Botrytis cinerea and Pseudomonas syringae pv. tomato. Only one PPO (ppo-2) was induced during infection, and ppo-2 promoter and $\beta$-glucuronidase marker gene fusions revealed strong induction of the gene surrounding lesions induced by $B$. cinerea. Specific RNAi silencing reduced ppo-2 expression only, and concomitantly increased plant susceptibility to $P$. syringae pv. tomato. At 4 days postinoculation, $P$. syringae pv. tomato populations were strongly increased in the ppo-2 RNAi lines compared with wild-type plants. When the dandelion ppo-2 gene was expressed in Arabidopsis thaliana, a plant having no PPO gene, active protein was formed and protein extracts of the transgenic plants exhibited substratedependent antimicrobial activity against $P$. syringae pv. tomato. These results clearly indicate a strong contribution of a specific, single PPO isoform to disease resistance. Therefore, we propose that specific PPO isoenzymes be included in a new family of pathogenesis-related (PR) proteins.
\end{abstract}

In their long association with pathogens, plants evolved an intricate and elaborate array of defensive tools. The resistance mechanisms exhibited by plants can be grouped as constitutive and inducible, and they range from structural to chemical defenses. Most of these mechanisms are exhibiting a passive role, others are highly active against pathogens, aiming at the

Carolin Richter and Mareike E. Dirks contributed equally to this work.

Corresponding author: B. M. Moerschbacher; Telephone +49 (0)2 5183 24 79 4; Fax: +49 (0)2 51822837 1; E-mail: moersch@uni-muenster.de

Nucleotide sequence data is available in the GenBank database under accession numbers EU154993 (ppo-1), FM178478 (ppo-2), FR822522 (ppo3), FR822523 (рpo-4), FR822524 (рpo-5), HE573569 (ppo-2I) and HE573570 (ppo-2II).

* The $\boldsymbol{e}$-Xtra logo stands for "electronic extra" and indicates that three supplementary figures are published online. fungal cell wall, plasma membrane, or intracellular targets. One example of such an active chemical defense response would be the induction of pathogenesis-related (PR) proteins with antimicrobial activities, such as chitinases or defensins (Ferreira et al. 2007; Hammond-Kosack and Jones 1996). As each defensive mechanism was established in the plant, new ways to break or circumvent it evolved in the pathogen. However, some plants possess particularly successful strategies of pathogen defense, making them resistant against most pathogens. One such plant is dandelion (Taraxacum officinale), an adaptable weed widely distributed throughout Europe, Asia, and America. T. officinale is an almost stemless, lactiferous herb used as a food source (Escudero et al. 2003) and as a medicinal plant (Stewart-Wade et al. 2002). T. officinale has a cytogenetic characteristic, namely a ploidy level ranging from diploid to hexaploid (Richards 1973). In Europe, T. officinale shows a north-polyploid (mainly triploid, asexual) south-diploid (sexual) contrast of geographical distribution (van Dijk 2003). The triploid, apomictically reproducing plants generate genetically identical offspring (van Dijk and Bakx-Schotman 2004). As a consequence, low levels of genetic variation are expected in northern Europe. In contrast to genetically uniform monocultures of agricultural crops that are threatened by massive appearance of pest and pathogenic organisms, there are no reports of major emergences of diseases in a more or less genetically homogeneous population of $T$. officinale.

We are interested in elucidating the molecular basis of this pronounced disease resistance in dandelion. As we found this plant to exhibit high polyphenol oxidase (PPO) activity and PPO have been implicated in resistance against pests and pathogens, we analyzed the potential involvement of five PPO isoenzymes in the resistance of dandelion. PPO are plastid-localized copper metalloenzymes catalyzing the oxidation of $o$-diphenols to $o$-diquinones (diphenolase activity; EC 1.10.3.2), and in some plants, they may also perform the $o$-hydroxylation of monophenols (monophenolase activity; EC 1.14.18.1) (Mayer 2006; Vaughn et al. 1988). Quinones are highly reactive electrophiles responsible for much of the oxidative browning in fruits and vegetables (Yoruk and Marshall 2003). Recently, downregulation of PPO genes has been a successful approach to reduce browning in apple (shoot and callus) and potato tuber (Coetzer et al. 2001; Murata et al. 2000, 2001). PPO are also believed to 
function in wound healing (Walker and Ferrar 1998), stress tolerance (Thipyapong et al. 2004b), and latex coagulation (Wahler et al. 2009).

Although PPO are widely produced by plants, their biological function is still not completely clear (Mayer 2006). PPO have been postulated to serve as an important component of plant defenses against pests and pathogens (Mayer 1987, 2006; Mayer and Harel 1979; Thipyapong et al. 2007; Walker and Ferrar 1998). The antiherbivore role of PPO was first demonstrated in tomato by Felton and associates (1989), showing that PPO-generated quinones could alkylate dietary proteins and reduce their nutritive value for insect pests. In addition, overexpression of a wound- and herbivore-inducible leaf PPO in transgenic Populus strains resulted in enhanced resistance to forest tent caterpillar Malacosoma disstria (Wang and Constabel 2004). A correlation between PPO level and resistance to pathogens has been reported repeatedly, suggesting an involvement of PPO in resistance, e.g., of pearl millet (Penisetum glaucum) to downy mildew (Sclerospora graminicola) (Niranjan Raj et al. 2006). The first direct evidence of PPO being involved in resistance to pathogens came from transgenic tomato plants overexpressing PPO and exhibiting increased resistance to Pseudomonas syringae pv. tomato (Li and Steffens 2002). In addition, downregulation of PPO genes resulted in enhanced disease susceptibility to this pathogen in both compatible and incompatible interactions. A single antisense PPO construct was sufficient to downregulate all members of the tomato PPO gene family, as judged by hybridization of total mRNA with a probe that reacts with all members of the family (Thipyapong et al. 2004a).

Although it is generally believed that most biological effects of PPO are based on the reactive nature of the $o$-quinones produced, the mechanism is far from being fully understood. In particular, detailed analysis of individual members of this gene family are lacking but are needed in order to dissect their involvement in different aspects of plant metabolism. In this study, we showed a selective induction of one PPO isoenzyme during pathogen attack in dandelion, and we produced T. officinale plants with a specific knockdown of this pathogeninduced PPO (ppo-2), using RNAi technology. The transgenic plants were inoculated with the bacteria $P$. syringae pv. tomato to evaluate whether PPO silencing results in reduced disease resistance. The antibacterial activity of this PPO isoenzyme and its products were analyzed in vitro, using recombinant enzyme produced in transgenic Arabidopsis thaliana, a model plant lacking PPO genes.

\section{RESULTS}

\section{Expression pattern of dandelion PPO genes.}

The expression pattern of five PPO genes was analyzed using reverse transcription-polymerase chain reaction (RT-PCR) in different tissues of dandelion (Taraxacum officinale) (Fig. 1A). Young plants (seven weeks old) were used for the analysis of roots and leaves. Because these plants produce only a small amount of latex and are not flowering, adult plants (older than six months) were also used to complete the study in latex, stalk, and flower. RT-PCR revealed a tissue-specific expression of four PPO genes. The ppo- 1 and ppo-3 genes are expressed in latex, and transcripts of both genes (except for ppo-3 in some adult plants) were also detectable in roots. In contrast, ppo-2 transcripts were only detected in roots, and the ppo-4 gene was very slightly expressed in stalk and flower. mRNA of the ppo-5 gene was not detected in any of the tissues tested.

To investigate whether transcription of any of these genes is induced after pathogen attack, leaves of young dandelion plants were inoculated with two different pathogens, namely the necrotrophic fungus Botrytis cinerea and the hemibiotrophic bacte- rium $P$. syringae pv. tomato. $B$. cinerea is a pathogen with a broad host range comprising more than 200 species of dicot plants (Elad et al. 2004), including T. officinale (Stewart-Wade et al. 2002). Seven-week-old plants were inoculated by spraying
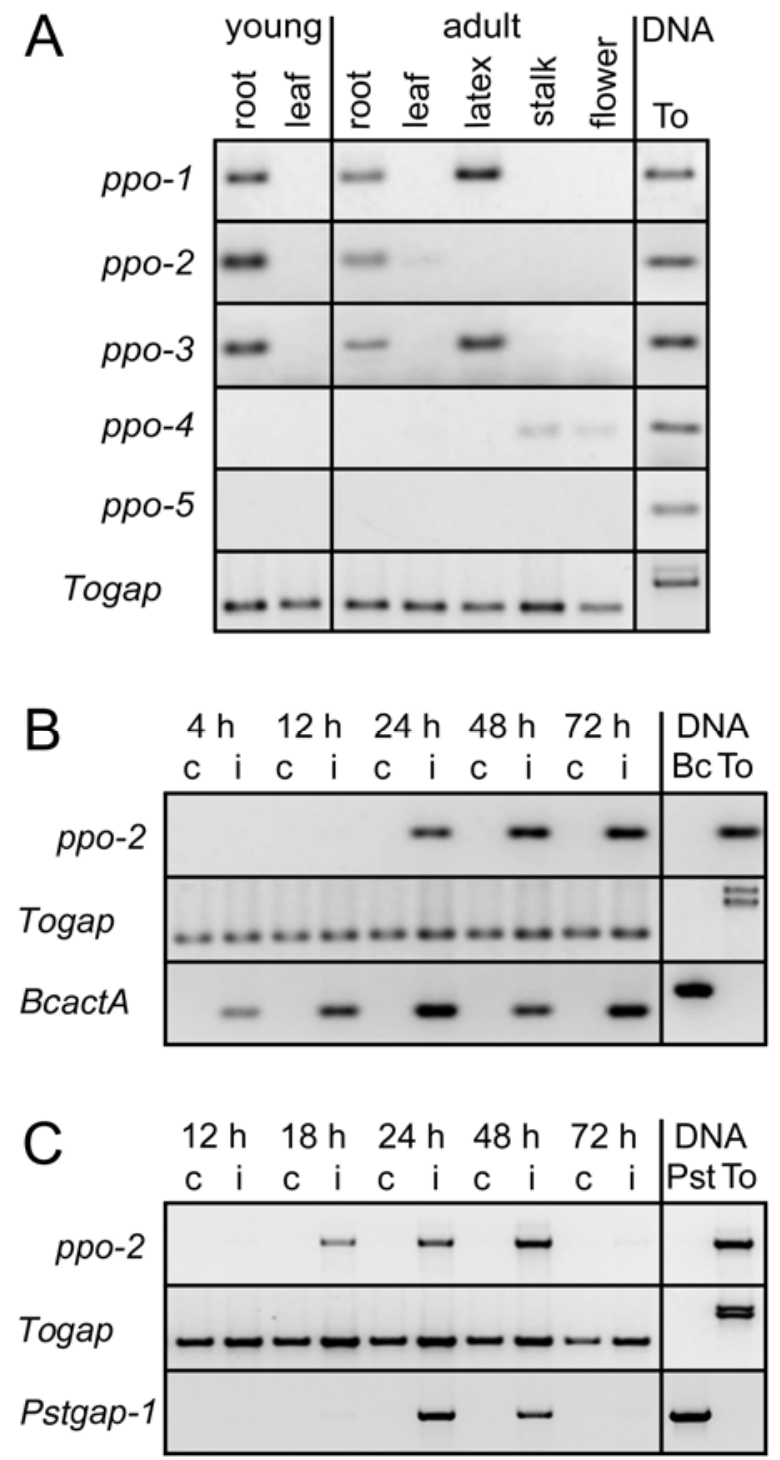

Fig. 1. Reverse transcription-polymerase chain reaction (PCR) analysis of polyphenol oxidase (PPO) expression in Taraxacum officinale. As a control for PCR conditions, PCR was performed in parallel on genomic DNA (DNA) as template. A, Expression pattern of the five PPO in different tissues of $T$. officinale. RNA was harvested from young (6 to 8 weeks old) and from adult plants (older than 6 months). RNA was obtained from roots, leaves, latex, stalks, and flowers as indicated. The T. officinale gap gene (Togap) served as a constitutively expressed control gene for equal loading of RNA. B, Analysis of ppo-2 expression after inoculation (i) with Botrytis cinerea. Inoculation of 7-week-old $T$. officinale plants was performed by spraying a conidia suspension $\left(10^{6}\right.$ conidia per milliliter) to the leaf surface. Control plants (c) were treated with medium only. The RNA was isolated from leaves harvested at 4, 12, 24, 48, and $72 \mathrm{~h}$ postinoculation (hpi). Expression of Togap served as a constitutively expressed control gene for equal loading of RNA, and $B$. cinerea actA (BcactA) was used as a control for the growth of $B$. cinerea in dandelion leaves. C, Expression of ppo-2 after inoculation (i) of 7-week-old $T$. officinale leaves with a bacterial suspension $\left(2 \times 10^{6} \mathrm{CFU}\right.$ $\mathrm{ml}^{-1}$ ) of $P$. syringae pv. tomato. Control plants (c) were treated with buffer only. The RNA was isolated from leaves harvested at 12, 18, 24, 48, and 72 hpi. Again, Togap serves as a constitutively expressed control gene for equal loading of RNA, and $P$. syringae pv. tomato gap- 1 was used as a constitutively expressed control gene for the growth of $P$. syringae pv. tomato in dandelion leaves. $T o=T$. officinale, gap = glyceraldehyde-3-phosphate dehydrogenase, $\mathrm{Bc}=B$. cinerea, act $A=$ actin, and $\mathrm{Pst}=P$. syringae $\mathrm{pv}$. tomato . 
a suspension of $10^{6}$ conidia per milliliter to the leaf surface. The leaves were harvested at five different time points $(4,12,24,48$, and $72 \mathrm{~h}$ postinoculation [hpi]), and RT-PCR analysis revealed that, of the five PPO genes investigated, only the ppo-2 gene was induced during infection, starting 24 hpi (Fig. 1B; Supplementary Fig. 1A), i.e., concomitant with the appearance of the first primary lesions. Similarly, T. officinale plants were inoculated by dipping the leaves into an inoculum of $2 \times 10^{6} \mathrm{CFU}$ of $P$. syringae pv. tomato per milliliter, and leaves were harvested at five different time points $(12,18,24,48$, and $72 \mathrm{~h}) . P$. syringae pv. tomato is the causative agent of tomato bacterial speck disease, and it has not been reported as a pathogen of T. officinale. Similar to $B$. cinerea, the bacterium induced expression of the ppo-2 gene (Fig. 1C). Amplified transcripts of ppo-2 were obtained for 18 to 48 hpi only. As indicated by the transcript levels obtained for the constitutively expressed bacterial $P$. syringae pv. tomato gap- 1 gene, the number of bacteria cells first increased with a maximum at $24 \mathrm{hpi}$ and then decreased. To see whether ppo-2 induction is specific for pathogen attack, the expression of the five PPO genes was also analyzed after wounding of dandelion leaves. The leaves were harvested at different time points (5 and $10 \mathrm{~min}$ and $0.5,1,2,4$, and $10 \mathrm{~h}$ after wounding), but wounding did not induce the expression of any of these five PPO genes (Supplementary Fig. 2).

\section{ppo-2 promotor activity.}

For further analysis of this pathogen-induced PPO, the complete $p p o-2$ gene, including its promoter, was isolated. As a feature common to most PPO genes, the ppo- 2 open reading frame (ORF) of $1,785 \mathrm{bp}$ codes for a transit peptide targeting the mature protein to the thylakoid lumen, and the gene contains no intron. The predicted PPO- 2 protein has two conserved copper-binding domains, $\mathrm{CuA}$ and $\mathrm{CuB}$, responsible for copper coordination and interaction with molecular oxygen and phenolic substrates (Supplementary Fig. 3). Two promoter fragments (ppo-2I [1,948 bp], and ppo-2II [2,059 bp]) were isolated. They are $94 \%$ identical but differ in some deletions and nucleotide exchanges.

To study the activity of the two ppo-2 promoters during fungal infection, transgenic dandelion plants were generated, expressing the gusA gene under the control of the ppo-2 promoters. A total of 20 phosphinotricin-resistant independent $T$. officinale transformants were generated by Agrobacterium tumefaciens-mediated leaf disk transformation. Primary 4-weekold transformants were assayed for $\beta$-glucuronidase (GUS) activity after inoculation with $B$. cinerea. Based on best GUS activity, transformants ppo-2I-8 and ppo-2II-12 were selected for further experiments. Inoculations of plants were performed by applying $10-\mu \mathrm{l}$ droplets of a conidia suspension $\left(10^{6} \mathrm{co}-\right.$ nidia per milliliter) to the leaf surface of detached leaves. Within $24 \mathrm{hpi}$, symptoms of the disease began to appear as brown spots on the surface of the inoculated leaf. Figure $2 \mathrm{~A}$ shows the appearance of typical lesions at $48 \mathrm{hpi}$. The lesions continued to increase in size with time until the whole leaf was colonized by the fungus. The induction of the ppo-2 promoters was monitored by staining infected leaf tissue with 5-bromo-4chloro-3-indolyl glucuronide (X-gluc), the substrate for GUS. GUS activity was first detected $24 \mathrm{hpi}$, appearing in cells at the
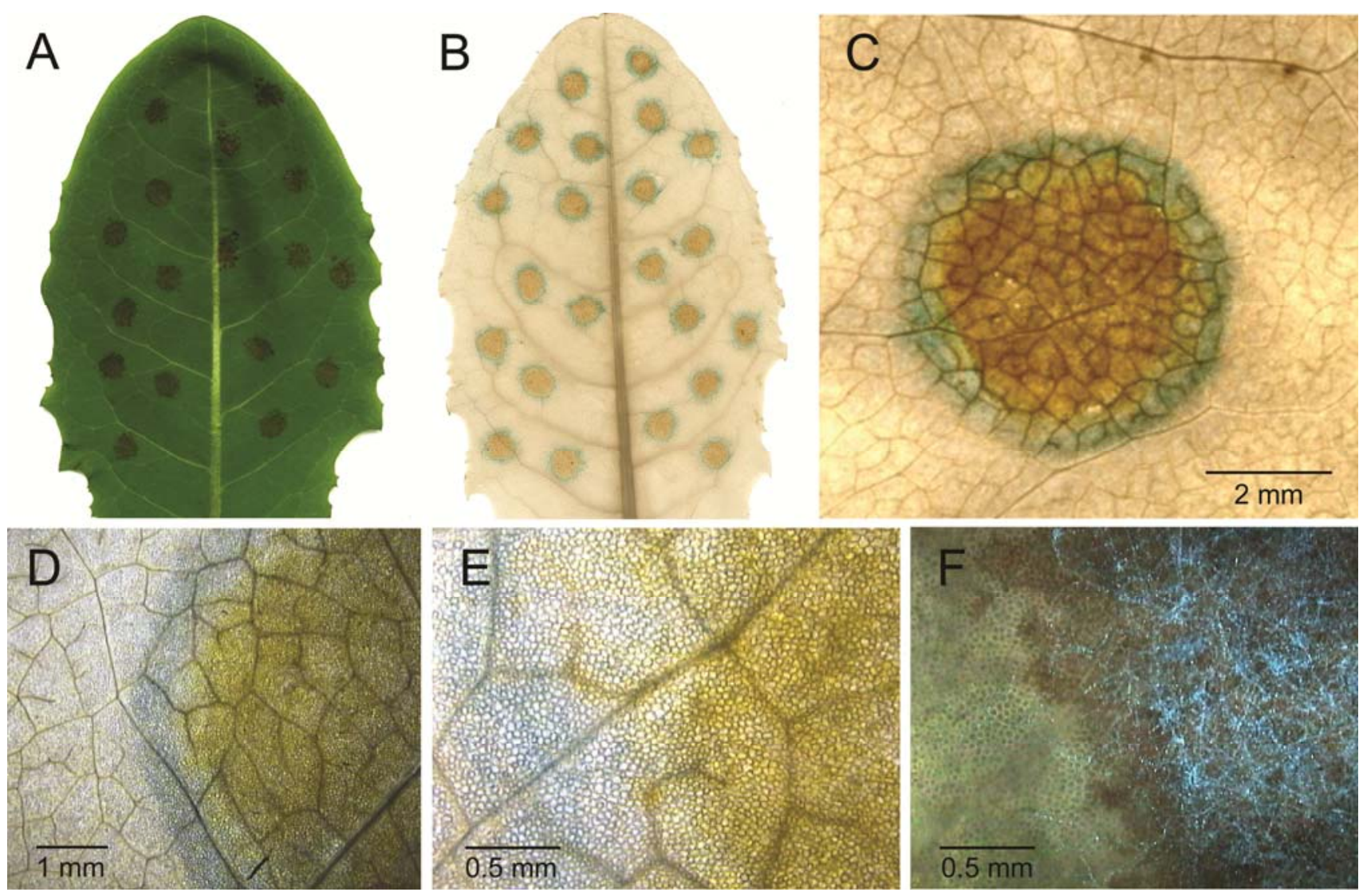

Fig. 2. Histochemical staining of $\beta$-glucuronidase (GUS) activity in transgenic Taraxacum officinale leaves inoculated with Botrytis cinerea. A, Typical appearance of lesions $48 \mathrm{~h}$ postinoculation (hpi) produced by B. cinerea. Inoculations of plants were performed by applying $10-\mu 1$ droplets of a conidia suspension (10 ${ }^{6}$ conidia per milliliter) to the leaf surface of a detached dandelion leaf. B and $\mathbf{C}$, Histochemical GUS activity staining of transgenic $T$. officinale leaves expressing the gusA gene under the control of the ppo-2 promoter 48 hpi with B. cinerea. After staining, the leaf was destained with $20 \%$ chloroform in EtOH. $\mathbf{D}$ and $\mathbf{E}$, Visualization of cells expressing GUS. The area shown represents a part of the lesion and the GUS positive tissue surrounding the lesion. Samples were observed using a light microscope. F, Fluorescence detection of fungal hyphae stained with calcofluor white in the lesion shown in E. 
periphery of the developing lesion, but staining was also evident within the lesion itself. As the infection progressed, the region showing positive staining increased in size and localized around the site of fungal infection. Figure 2B, C, and D show the GUS staining $48 \mathrm{hpi}$. The two promoters (ppo-2I and ppo-2II) showed no difference in activity. GUS activity was neither observed in the wild type nor in control transformants, indicating that this activity was not due to secondary infection by microorganisms possessing GUS activity. To localize the fungus, fungal hyphae were stained with calcofluor white and were then visualized under a fluorescence microscope. As expected, a large number of fungal hyphae were found in the lesion itself (Fig. 2E and F) and fewer hyphae were seen in the GUS-stained ring of cells surrounding the lesion. No fungal mycelia were visible beyond this area.

In a different approach, 8-week-old T. officinale plants were inoculated with the bacteria $P$. syringae pv. tomato by dipping
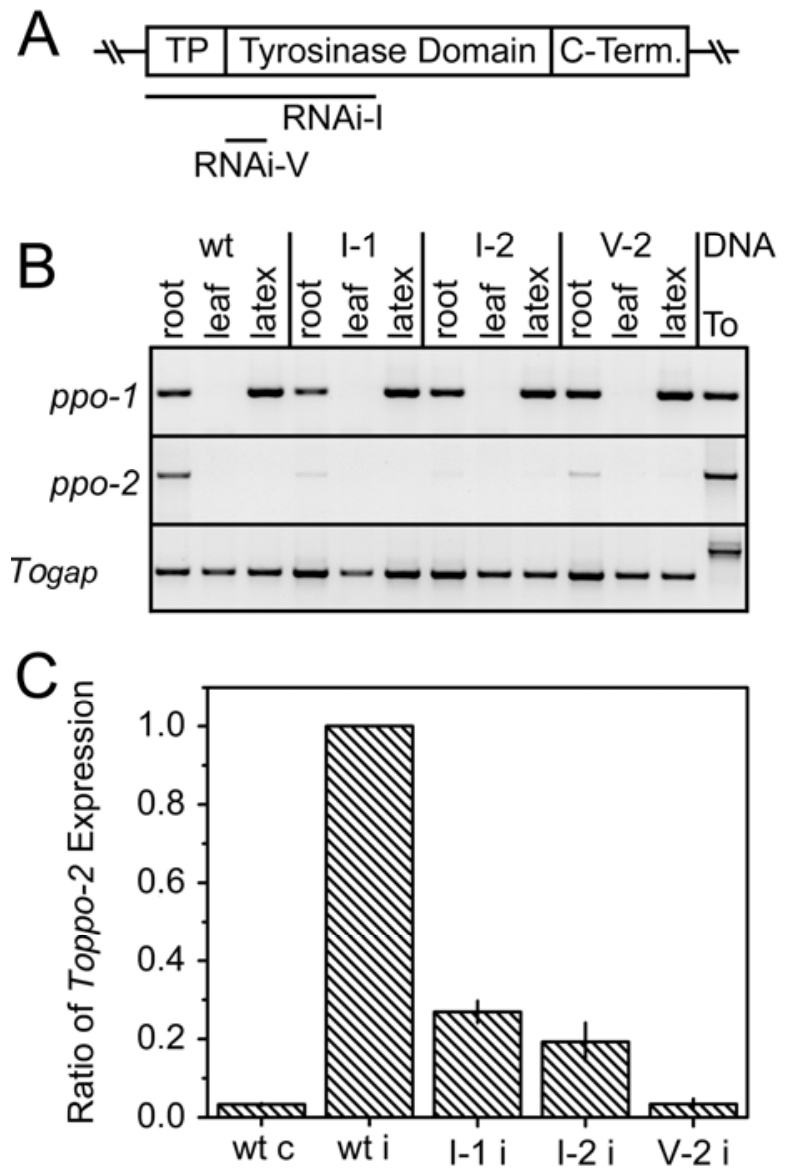

Fig. 3. Analysis of ppo-2 expression in wild-type and RNAi-knockdown Taraxacum officinale plants. A, Position of the sequence fragments (RNAi-I and RNAi-V) for the RNAi constructs in the ppo-2 gene. TP = transit peptide for the thylakoid lumen of chloroplasts, $\mathrm{C}$-Term. $=\mathrm{C}$ terminus. B, Reverse transcription-polymerase chain reaction (PCR) analysis of ppo1 and ppo-2 expression in different tissues of $T$. officinale plants. RNA was harvested from adult plants (older than 6 months) obtained from roots, leaves, and latex as indicated. The T. officinale glyceraldehyde-3-phosphate dehydrogenase gene (Togap) served as a constitutively expressed control gene for equal loading of RNA. As a control for PCR conditions, PCR was performed in parallel on genomic DNA as template. C, Quantitative real time PCR analysis of ppo-2 expression. RNA was isolated from leaves harvested $48 \mathrm{~h}$ postinoculation (i) with $B$. cinerea. Inoculation of 6 to 8 -week-old plants was performed by spraying a conidia suspension $\left(10^{6}\right.$ conidia per milliliter) to the leaf surface. Wild-type control plants (c) were treated with medium only. For normalization, Togap was used as a constitutive reference. Data are means of two independent experiments; bars represent the range of measurements. the leaves into an inoculum $\left(2 \times 10^{6} \mathrm{CFU} \mathrm{m}^{-1}\right)$, and the leaves were harvested at 24 and 48 hpi. Similar to inoculation with $B$. cinerea, GUS activity was seen in infected transformed leaves only, confined to small, diffuse leaf regions spread over the whole leaf (data not shown).

\section{Infection studies on ppo-2 knockdown plants.}

To investigate the relationship between the pathogen-induced PPO-2 activity and resistance of dandelion, RNAi constructs were designed to target the first part of the ppo-2 gene (RNAiI, $846 \mathrm{bp}$ ) or the first part of the tyrosinase domain (RNAi-V, $141 \mathrm{bp}$ ) (Fig. 3A). The two constructs were expressed under the control of the Cauliflower mosaic virus (CaMV) 35S promoter (Guilley et al. 1982) and nos terminator. A total of 25 phosphinotricin-resistant independent $T$. officinale transformants were generated by Agrobacterium tumefaciens-mediated leaf-disk transformation. Transgene integration and transcription were confirmed by PCR and RT-PCR, respectively. As expected, there was great variability in the efficiency of ppo-2 knockdown, ranging from almost complete abolition of ppo-2 expression after inoculation with $B$. cinerea to nearly wild-type levels. Transformed plants did not show any obvious differences in growth, development, or seed production compared with the nontransformed controls. Three independent transformants (I-1, $\mathrm{I}-2$, and V-2) displaying a specific downregulation of the ppo-2 gene were chosen for further studies. The specificity of the knockdown was tested using RT-PCR analysis (Fig. 3B) on RNA isolated from different tissues (root, leaf, and latex) of noninfected wild-type and knockdown plants. The knockdown had no influence on ppo-1 expression in root and latex, only the ppo-2 expression in roots was reduced in the transformants compared with the wild type. Figure $3 \mathrm{C}$ presents real-time PCR analysis from these three transformants 48 hpi of the leaves with $B$. cinerea. Transgenic line I-1 showed a 3.71-fold decrease in ppo- 2 expression in comparison to the wild type, line I-2 a 5.19-fold decrease, and the highest knockdown rates were shown by line V-2 (29.73-fold decrease), reaching a level of ppo-2 expression similar to that in wild-type control plants.

If PPO-2-catalyzed phenolic oxidation is involved in disease resistance, a knockdown of the ppo-2 gene in $T$. officinale can be expected to lead to enhanced disease susceptibility to pathogens. To examine potential differential responses to pathogens of wild-type and knockdown plants, $P$. syringae pv. tomato, to which the wild type is resistant under these conditions (Fig. 1C),

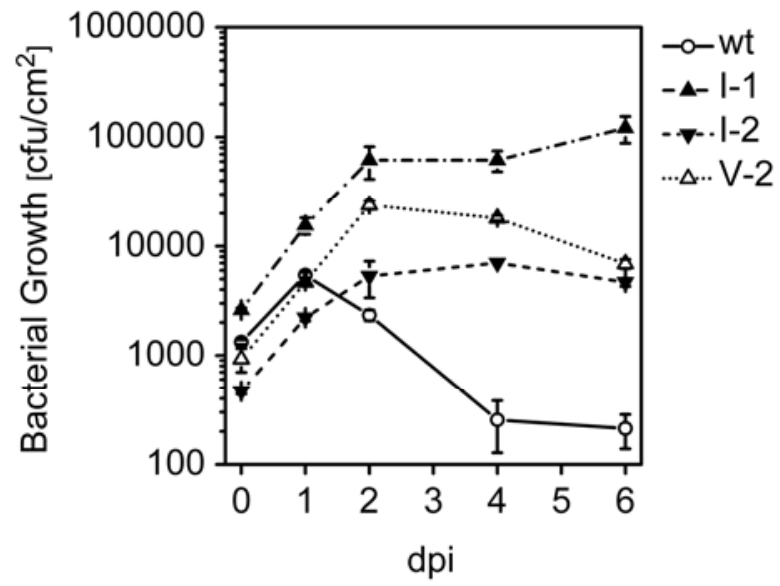

Fig. 4. Bacterial growth in wild-type Taraxacum officinale plants and three transgenic dandelion lines. Plants were inoculated with $P$. syringae pv. tomato at $2 \times 10^{6} \mathrm{CFU} \mathrm{ml}^{-1}$, and bacterial growth was determined at $0,1,2$, 4 , and 6 days postinoculation. The experiment was repeated three times with different plant batches. Data given are means \pm standard deviation of triplicate samples from one representative of three independent experiments. 
was chosen for this study. All three independent transgenic lines and nontransformed control plants were inoculated by dipping the leaves into an inoculum of $2 \times 10^{6} \mathrm{CFU}$ of $P$. syringae pv. tomato per milliliter. Bacterial growth was determined over a period of 6 days postinoculation (dpi). As depicted in Figure 4, all three transgenic lines showed supported increased bacterial growth compared with the wild-type plants. At 4 dpi, bacterial populations were 28 - to 242 -fold in the transgenic lines as compared with the wild-type plant. While absolute bacterial growth varied from experiment to experiment, the transformants showed significantly higher growth compared with the wild type in all experiments. $P$. syringae pv. tomato did not induce clear symptoms on infected dandelion leaves. In wild-type plants, there were almost no symptoms visible and, even on the more susceptible knockdown plants, only very small watersoaked lesions and, later, tiny necrotic lesions can be observed (data not shown).

Similar experiments were performed by inoculating the leaves of wild-type and knockdown plants with $B$. cinerea. Here, we could not observe any differences between the ppo-2 knockdown plants and the wild type.

\section{Heterologous expression of PPO-2 in A. thaliana.}

To assess the antimicrobial potential of PPO-2, the ppo-2 cDNA was placed under the control of the CaMV $35 \mathrm{~S}$ promoter and nos terminator and was introduced into A. thaliana
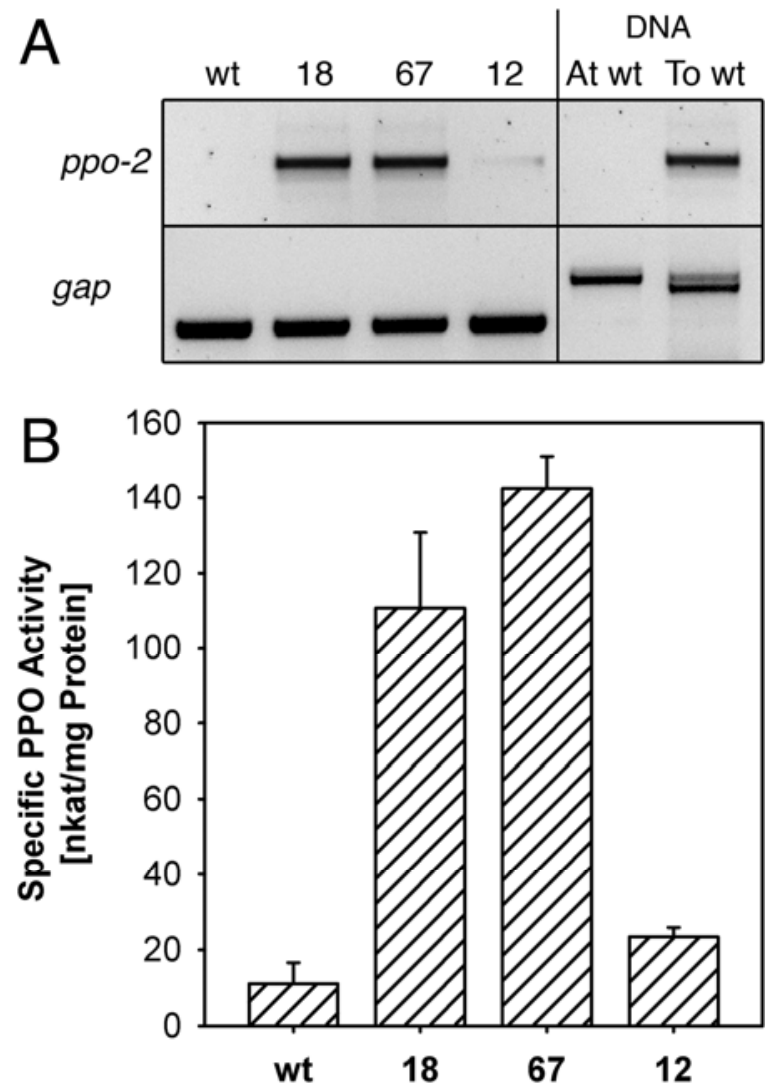

Fig. 5. Analysis of ppo-2 expression and activity in wild-type Arabidopsis thaliana plants and three transgenic lines. A, Reverse transcription-polymerase chain reaction (PCR) analysis of ppo-2 expression in 4-week-old $A$. thaliana plants. The gap (glyceraldehyde-3-phosphate dehydrogenase) gene served as a constitutively expressed control gene for equal loading of RNA. As a control for PCR conditions, PCR was performed in parallel on genomic DNA as template. gap $=A$. thaliana gapc-2 and Taraxacum officinale gap, At $=$ A. thaliana, To $=T$. officinale . B, Polyphenol oxidase (PPO) activity measurement with dopamine as a substrate of leaf extracts from 4-week-old A. thaliana plants. Data given are means \pm standard deviation of triplicate samples from one representative of three independent experiments. plants by Agrobacterium tumefaciens-mediated transformation. We chose A. thaliana because no genes coding for PPO were detected in the genome of this model plant (Mayer 2006). For heterologous ppo-2 expression, the gene was transformed with the original dandelion transit peptide for the thylakoid lumen, so that the enzyme should be separated from potential phenolic substrates typically localized in the vacuole. More than 80 kanamycin-resistant independent transformants were produced. Under controlled conditions, growth and reproduction of the PPO-expressing transgenic plants did not visually differ from those of nontransformed control plants. The $\mathrm{T}_{1}$ generation was further analyzed using RT-PCR for expression of ppo-2, and the expression level of the ppo-2 gene was found to correlate with PPO activity. Selected independent transformants were selfed to produce $\mathrm{T}_{2}$ plants for further studies. In Figure 5, ppo-2 expression and PPO activity from leaves of three $\mathrm{T}_{2}$ plants (lines 18, 67, and 12) are shown as an example. Consistent with the abundance of PPO transcripts, transgenic lines 18 and 67 showed a 9.4- and 12.1-fold increase in activity compared with the wild-type plants and the transgenic line 12 a 2.0-fold increase. The absolute levels of PPO activity of these transgenic plants, measured in the presence of catalase to eliminate the contribution of peroxidase activity to phenolic oxidation, appeared to vary from experiment to experiment according to plant developmental stage and growth conditions. However, in all experiments, the relative ranking between the lines remained the same.

Infection studies on the PPO-expressing transgenic A. thaliana plants were performed, using both $B$. cinerea and $P$. syringae pv. tomato. For both pathogens, no differences in disease severity could be observed comparing wild-type and ppo-2 expressing plants (data not shown).

\section{Antimicrobial activity of PPO-2 containing leaf extracts.}

The antimicrobial activity of the recombinant PPO-2 enzyme and its products was assessed in vitro in a microtiter plate-based bioassay using $P$. syringae pv. tomato, the growth of which was increased in pро-2 knockdown plants of dandelion compared with wild-type plants (Fig. 4). Untreated or heat-inactivated leaf extract of the independent transgenic lines 18 and 67, both expressing the ppo-2 gene at a high level (Fig. 5) and of nontransformed control plants were added to minimal medium containing $P$. syringae pv. tomato and $1 \mathrm{mM}$ dopamine as a PPO substrate. Following incubation for $7 \mathrm{~h}$, bacterial growth was determined by diluting the samples in fresh minimal medium supplemented with $0.05 \%$ peptone, followed by measuring the optical density at $600 \mathrm{~nm}\left(\mathrm{OD}_{600}\right)$ over a period of $16 \mathrm{~h}$. As a negative control, we used the extraction buffer $(50 \mathrm{mM}$ Trismaleate buffer, $\mathrm{pH}$ 6.0) instead of the leaf extract. Here, bacterial growth was slightly delayed due to the missing protein source in the minimal medium. A second control contained leaf extract of $A$. thaliana wild-type plants. Neither the untreated wild-type extract nor heat-inactivation of this extract or the addition of $1 \mathrm{mM}$ dopamine leads to a delay in bacterial growth. This concomitantly shows that the control leaf extract did not contain any antibacterially active compound and that dopamine alone does not affect bacterial growth. In contrast, the PPO-containing extracts from transgenic lines 18 and 67 possessed an antibacterial effect visible as delayed growth of the bacteria (Fig. 6B). This antibacterial effect was dependant on the addition of a PPO substrate (Fig. 6A), and it was eliminated by heat inactivation of the leaf extracts prior to incubation with bacteria (Fig. 6C). The corresponding PPO activity in the untreated and heat-inactivated extracts used is shown in Figure 6D. This substrate-dependent antibacterial effect was not specific for dopamine but was also visible with other model substrates, such as L-dihydroxy-phenylalanine (data not shown). 


\section{DISCUSSION}

In the past, PPO have been extensively studied in plants for their roles in browning reactions of fruit and vegetable after wounding and during processing and, to a lesser extent, for their functions in plant defense against pests and pathogens (Mayer 1987, 2006; Mayer and Harel 1979; Thipyapong et al. 2007; Walker and Ferrar 1998).

However to our knowledge, PPO have not been included in the families of PR proteins (van Loon et al. 2006). This is most likely due to the fact that PPO activity can typically be found in healthy tissues, too, and it often increases upon wounding or during other stress responses. We are not aware of any functional studies investigating the physiological roles of individual PPO isoenzymes. However, following currently accepted terminology, a protein can only be classified as a PR protein if its de novo induction from nondetectable levels in a healthy plant tissue can unequivocally be shown in infected tissues (van Loon et al. 1994). We here present evidence of such an induction of the ppo-2 gene in dandelion ( $T$. officinale) leaves upon infection with bacteria and fungi. The induction of ppo-2 appears to be infection-specific, since no induction was observed after wounding, and all other known PPO genes (ppo-1, ppo-3, ppo-4, and ppo-5) did not show any induction after pathogen attack or severe wounding. PR proteins have previously been shown to be rapidly induced locally around infection sites. As an example, Roby and associates (1990) reported the induction of a bean chitinase promoter in transgenic tobacco plants infected with $B$. cinerea utilizing GUS as a reporter gene; the highest promoter activity was found within the necrotic region itself. Similarly, previous studies have shown that PPO activity is locally increased to high levels during resistance responses, e.g., in cells surrounding infection-induced lesions, implying that PPO may contribute to the hypersensitive cell-death response. Bashan and associates (1987) have shown that PPO activity of tomato seedlings inoculated with $P$. syringae pv. tomato was relatively high only very close to the necrotic areas, and the PPO-F promoter was induced locally in tomato cells surrounding $P$. syringae pv. tomato lesions and Alternaria solani penetration sites (Thipyapong and Steffens 1997). Similarly, transgenic $T$. officinale plants expressing a chimeric promoter-marker gene construct showed a high level of ppo-2 expression in response to infection by $B$. cinerea, localized around the lesion. Although the highly localized induction of the ppo-2 promotor suggests an involvement of the pathogen-induced PPO in defense, we are not able to demonstrate a role for this in containing the lesion or the fungal growth.

Based on our results, we would like to propose PPO-2 as the first member of a new family of PR proteins. The term PR protein was introduced in 1980 to designate any protein or protein isoform encoded by the host plant but induced only in pathological or related situations (Antoniw et al. 1980). This criterion is clearly met by the ppo-2 gene, which is silent in healthy leaves and which is induced upon inoculation with $B$. cinerea and $P$. syringae pv. tomato. Using GUS fusion constructs, Thipyapong and Steffens (1997) showed that mechanical wounding and infection by Alternaria solani and P. syringae pv. tomato induced the transcription of PPO-F in tomato. In pearl millet (Pinesetum glaucum), an additional PPO isoenzyme was found after inoculation with downy mildew (Sclerospora graminicola) (Niranjan Raj et al. 2006). In the light of our study, these previous reports strongly argue in favor of defining a new family of PR proteins containing specific PPO isoenzymes.

In tomato, the importance of PPO-mediated phenolic oxidation in disease resistance was demonstrated using PPO-overexpressing transgenic plants that became more resistant to bacterial attack (Li and Steffens 2002). Conversely, antisense downregulation of all members of the tomato PPO gene family resulted in enhanced disease susceptibility towards the same bacteria (Thipyapong et al. 2004a). In contrast to nonspecific antisense downregulation of all PPO genes in that study, we
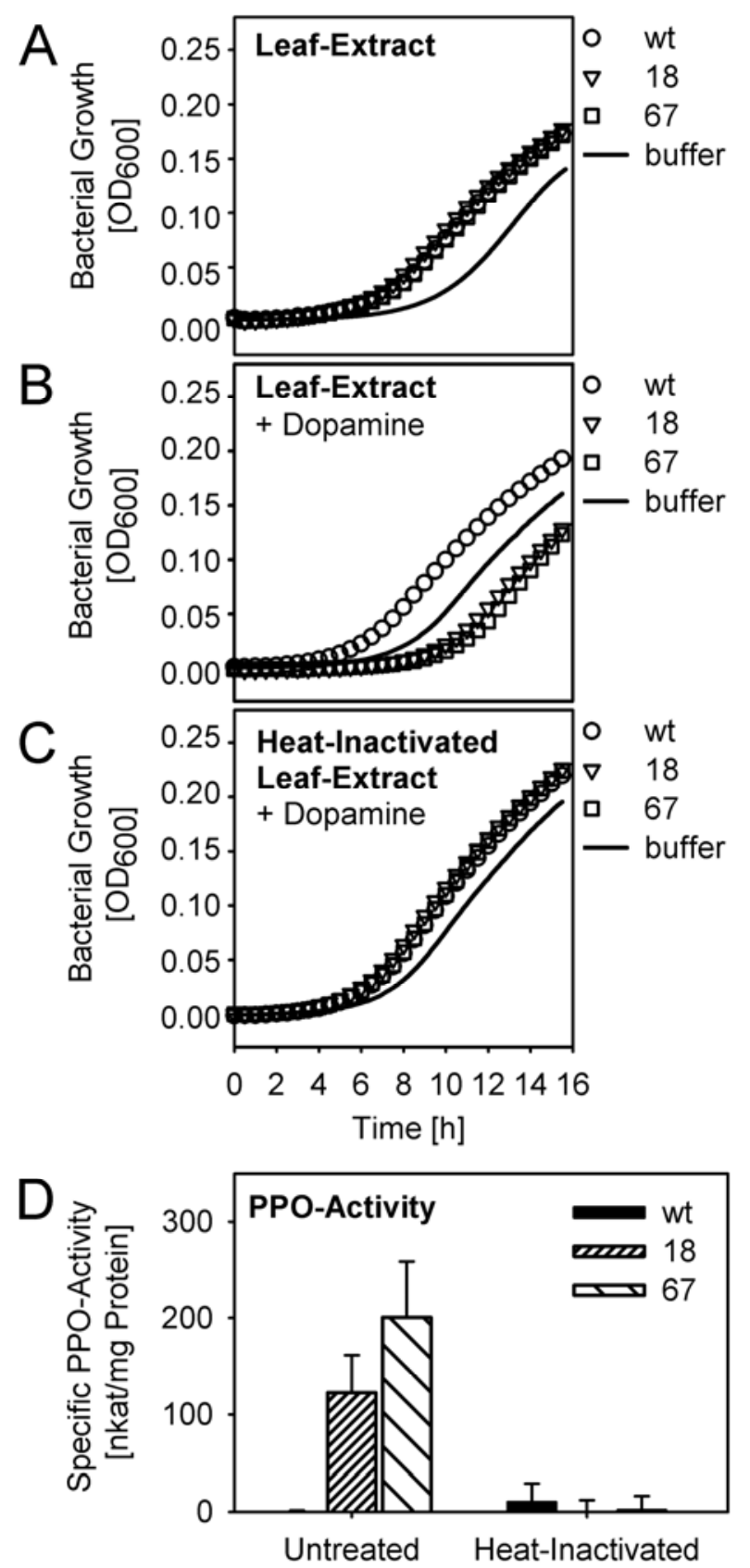

Fig. 6. Antibacterial test with leaf extracts of transgenic and wild-type Arabidopsis thaliana plants. Untreated or heat-inactivated leaf extracts (30 $\mu \mathrm{l}$ with protein content of $1 \mathrm{mg} \mathrm{ml}^{-1}$ ) of two transgenic lines (18 and 67) and of wild-type $A$. thaliana plants (wt) were added to minimal medium containing Pseudomonas syringae pv. tomato and dopamine as substrate, when indicated. After incubation at $28^{\circ} \mathrm{C}$ for $7 \mathrm{~h}$ and $200 \mathrm{rpm}$ (Multitron2), the samples were diluted in fresh minimal medium supplemented with $0.05 \%$ peptone in 96-well microplates, and bacterial growth was monitored by measuring the optical density at $600 \mathrm{~nm}\left(\mathrm{OD}_{600 \mathrm{~nm}}\right)$ for $16 \mathrm{~h}$. As a negative control, we used the extraction buffer $(50 \mathrm{mM}$ Tris-maleate buffer, $\mathrm{pH}$ 6.0) instead of the leaf extract. Data given are means of triplicate samples from one, representative of three independent experiments. A, No substrate was added. B, Dopamine $(1 \mathrm{mM})$ was added as a substrate. C, Leaf extracts were heat-inactivated $\left(10 \mathrm{~min}, 100^{\circ} \mathrm{C}\right)$ and $1 \mathrm{mM}$ of dopamine was added as a substrate. D, Analysis of PPO-2 activity in the leaf extract was done using $1 \mathrm{mM}$ dopamine as a substrate. Data given are means \pm standard deviation of triplicate samples. 
specifically silenced the pathogen-induced ppo-2 gene using an RNAi approach. In this study, T. officinale plants exhibiting specific ppo-2 downregulation showed significantly higher susceptibility to $P$. syringae pv. tomato. In order to investigate the antimicrobial potential of PPO-2, we expressed the ppo-2 gene in A. thaliana, a model plant species possessing no PPO genes (Mayer 2006). While heterologous expression of recombinant PPO proved to be difficult in the past (Mayer 2006; Sullivan et al. 2004; Wu et al. 2010), the transgenic plants expressing the ppo-2 gene produced active PPO enzyme. Leaf extract from transgenic $A$. thaliana plants expressing the ppo-2 gene exhibited substrate-dependent antibacterial activity towards P. syringae pv. tomato, while leaf extract of wild-type plants did not. Our results show that neither the PPO-2-containing leaf extract nor the substrate alone possess an antibacterial effect, but the combination of both does (given that the enzyme is active). These findings strongly support the thesis that the PPO-produced quinones are the active substances. These results, showing for the first time an indirect substrate-dependent antibacterial effect of a pathogen-induced PPO, strongly support the notion of PPO involvement in disease resistance.

PPO-2-expressing A. thaliana plants did not possess resistance to $P$. syringae pv. tomato during infection studies (data not shown), which could be explained by the lack of an appropriate PPO substrate in A. thaliana leaves. The natural substrate for the PPO-2 in dandelion is not yet known. Diphenolic flavonoids are discussed to be the natural PPO substrates in plants (Pourcel et al. 2007), and dandelion is rich in such compounds (Williams et al. 1996). As a consequence, extracts from dandelion leaves quickly turn brown on air. In contrast, this is not the case with extracts from the PPO-expressing A. thaliana lines, indicating the lack of a suitable PPO substrate.

PPO appear to be located predominantly in the thylakoid lumen within the chloroplast, while their phenolic substrates are typically found in the vacuoles or in the apoplast (Walker and Ferrar 1998). Pathogen attack often directly leads to decompartmentalization or indirectly during the process of hypersensitive cell death (Levine et al. 1996), resulting in PPOmediated oxidation of $o$-diphenols to $o$-quinones. PPO might thus be considered as a component of cell-death responses and $o$-quinone production as one of the terminal events in the progression of such responses.

Quinones can act in a number of ways to protect plants against pathogens (Fig. 7). First, reactions of quinones and semiquinones with other phenolics can result in different condensation polymers able to seal off sites of infection or wounding, thus building up a physical barrier in the cell wall against an entry of pathogens (Walker and Ferrar 1998). Second, the ability of quinones to undergo 1,4-addition reactions with other cellular nucleophiles also provides the potential to alkylate proteins and to reduce protein bioavailability to pathogens (Felton et al. 1992). Third, the same reaction can inactivate phytotoxins, pathogenicity factors, or virulence factors produced by a pathogen (Walker and Ferrar 1998). Fourth, quinones and semiquinone radicals are able to carry out the single-electron reduction of molecular oxygen to form the superoxide anion radical $\left(\mathrm{O}_{2}^{-}\right)$, which may, in turn, give rise to other reactive oxygen species (ROS) (Thipyapong et al. 2004a). ROS produced in an oxidative burst have been proposed to contribute to resistance both directly by their antimicrobial effects and indirectly by activating further plant defense responses (Bolwell 1999; Lamb and Dixon 1997), and PPO-triggered ROS production may contribute to this complex response. In summary, PPO-generated quinones, semiquinones, and ROS can play a variety of defense-related functions simultaneously.

We have applied RNAi technologies and heterologous expression as powerful tools to conclusively establish an active role for an individual dandelion PPO isoenzyme in defense against pathogens. Since the different PPO isoenzymes appear to have different functions (Wahler et al. 2009), similarly detailed studies of other or all PPO isoenzymes will be needed to dissect and fully understand the actual roles of PPO in a given plant species.

\section{MATERIALS AND METHODS}

\section{Plant material, growth conditions, wounding, and inoculation with pathogens.}

Dandelion (Taraxacum officinale G.H. Weber ex Wiggers) and $A$. thaliana (ecotype Col-0) plants were grown in controlled growth chambers (16-h-day and 8-h-night and 8-h-day and 16-h-night cycle at 20 and $18^{\circ} \mathrm{C}$, respectively).

B. cinerea wild-type isolate B05.10 (Quidde et al. 1999) was grown on potato dextrose agar at room temperature under continuous fluorescent light supplemented with UV light for conidiation. Conidia were harvested from a 10-day-old culture and were suspended at a density of $10^{6}$ conidia per milliliter in sterile Gamborg B5-medium (Duchefa, Haarlem, The Netherlands), $2 \%$ glucose, and $10 \mathrm{mM} \mathrm{K}-\mathrm{P}_{\mathrm{i}}$ buffer ( $\mathrm{pH}$ 6.4). Inoculation of plants was performed by applying $10-\mu \mathrm{l}$ droplets of the conidia suspension to the leaf surface of a detached dandelion leaf. In a second approach, plants were inoculated by spraying conidia suspension onto the leaves with an airbrush. Controls were treated with sterile B5 medium, supplemented as above.

Pseudomonas syringae pv. tomato DC3000 was cultured in NYG medium (5 g of peptone, $3 \mathrm{~g}$ of yeast extract, and $20 \mathrm{ml}$ of glycerol per liter) containing $100 \mathrm{mg}$ of rifampicin and 25 $\mathrm{mg}$ of kanamycin per liter at $28^{\circ} \mathrm{C}$, until the beginning of the log phase $\left(\mathrm{OD}_{600}=0.2=\right.$ approximately $\left.10^{8} \mathrm{CFU} \mathrm{ml^{-1 }}\right)$. Bacteria were harvested by centrifugation $\left(10 \mathrm{~min}, 2,500 \times g, 20^{\circ} \mathrm{C}\right)$ and were washed with $10 \mathrm{mM} \mathrm{MgCl}_{2}\left(8 \mathrm{~min}, 2,500 \times \mathrm{g}, 20^{\circ} \mathrm{C}\right)$, and the pellet was resuspended in $5 \mathrm{mM} \mathrm{MgCl}_{2}$. T. officinale was inoculated by dipping the leaves into a bacterial suspension containing approximately $2 \times 10^{6} \mathrm{CFU} \mathrm{ml}^{-1}$ of $P$. syringae pv. tomato, $5 \mathrm{mM} \mathrm{MgCl}_{2}$, and $0.05 \%$ Silwet Gold (Spiess Urania, Hamburg, Germany) for $30 \mathrm{~s}$. Control plants were dipped in $5 \mathrm{mM} \mathrm{MgCl}_{2}$ and $0.05 \%$ Silwet Gold only.

Inoculated and control plants were incubated under a transparent plastic box to guarantee high humidity. At different time points after inoculation, leaves were harvested, were frozen in liquid nitrogen, and were used directly or stored at $-80^{\circ} \mathrm{C}$, as appropriate.

For wounding, leaves of 7-week-old dandelion plants were treated by rubbing them with sandpaper. Control plants were unwounded. RNA was isolated from leaves harvested at 5, 10, and $30 \mathrm{~min}$, and 1,2 , and $10 \mathrm{~h}$ postwounding and used for RTPCR analysis.

\section{Identification of ppo-1 to ppo-5, sequencing of ppo-2 and ppo-2I/II.}

Partial cDNA sequences corresponding to five $T$. officinale ppo genes were first amplified using PPO-specific degenerate primers LZ50 (5'-CAA MCA MCC TMC GTG TCC GGC C-3') and LZ45 (5'-TGG TGI AIG GRG GIC AAC AAT C-3') and genomic DNA as a template, extracted from young $T$. officinale leaves using the CTAB method (Doyle and Doyle 1990). DNA was digested with different restriction enzymes and self-ligated with T4 DNA ligase (Promega, Mannheim, Germany). Inverse PCR was performed using the recircularized genomic DNA as a template. Inverse PCR fragments were cloned into pGEM-T vector (Promega, Heidelberg, Germany) for sequencing.

The complete gene of the pathogen-induced ppo-2 $(1,785$ bp) was isolated using the Universal GenomeWalker kit (Clontech, Mountain View, CA, U.S.A.). PCR fragments were cloned 
and sequenced as above, yielding the full ppo-2 ORF. Chloroplast transit and thylakoid lumen-targeting signals were identified using the ChloroP algorithms (Emanuelsson et al. 1999).

Two promoter fragments (1,948 and 2,059 bp) were isolated using the Universal GenomeWalker kit (Clontech) and were cloned and sequenced as above. The fragments, representing the sequence immediately upstream of the ppo-2 translational start codon, were named ppo-2I and ppo-2II.

\section{RNA isolation and RT-PCR.}

Total RNA was isolated from frozen $T$. officinale tissues using a modified protocol from Chen and associates (2000). Ground tissue $(300 \mathrm{mg}$ ) was added to $0.09 \mathrm{~g}$ of polyvinylpolypyrrolidone and $375 \mu \mathrm{l}$ of homogenization buffer (4 M guanidine thiocyanate, $100 \mathrm{mM}$ Tris/ $\mathrm{HCl}[\mathrm{pH} 7.0], 2 \mathrm{M} \mathrm{NaCl}$ ), and was then mixed with $500 \mu \mathrm{l}$ prewarmed $\left(70^{\circ} \mathrm{C}\right)$ extraction buffer $(2 \%$ CTAB, $1 \%$ polyvinylpyrrolidone, $100 \mathrm{mM}$ Tris/ $\mathrm{HCl}[\mathrm{pH} 7.0]$, $25 \mathrm{mM}$ EDTA, $2 \mathrm{M} \mathrm{NaCl}$ ). Subsequently, RNA was extracted with an equal volume of phenol/chloroform (1:1) and was centrifuged at $8,000 \times g$ at $4^{\circ} \mathrm{C}$ for $25 \mathrm{~min}$. A second extraction was carried out with an equal volume of chloroform and was centrifuged for $15 \mathrm{~min}$ at $8,000 \times g$ and $4^{\circ} \mathrm{C}$. The RNA was precipitated with 0.5 volume $10 \mathrm{M} \mathrm{LiCl}$ at $4^{\circ} \mathrm{C}$ overnight, and was then harvested by centrifugation at $8,000 \times g$ and $4^{\circ} \mathrm{C}$ for $15 \mathrm{~min}$. The RNA pellet was washed once with $2 \mathrm{M} \mathrm{LiCl}$ and twice with $70 \% \mathrm{EtOH}$. Total RNA pellets were dissolved in $100 \mu \mathrm{l}$ of RNase-free water. RNA quantification was done spectrophotometrically and by gel electrophoresis.

Latex from T. officinale was harvested into $100 \mu \mathrm{l}$ of 100 $\mathrm{mM}$ Na- $\mathrm{P}_{\mathrm{i}}$ buffer ( $\mathrm{pH}$ 6.0), and total RNA was isolated using the peqGOLD TriFast kit (Peqlab Biotechnologie GmbH, Erlangen, Germany). Total RNA pellets were dissolved in $100 \mu \mathrm{l}$ of RNase-free water and were quantified as above.

Total RNA was isolated from frozen A. thaliana leaves using peqGOLD TriFast. Total RNA pellets were dissolved in $50 \mu \mathrm{l}$ of RNase-free water and were quantified as above.<smiles>[R]Oc1ccc(O)c(O)c1</smiles>

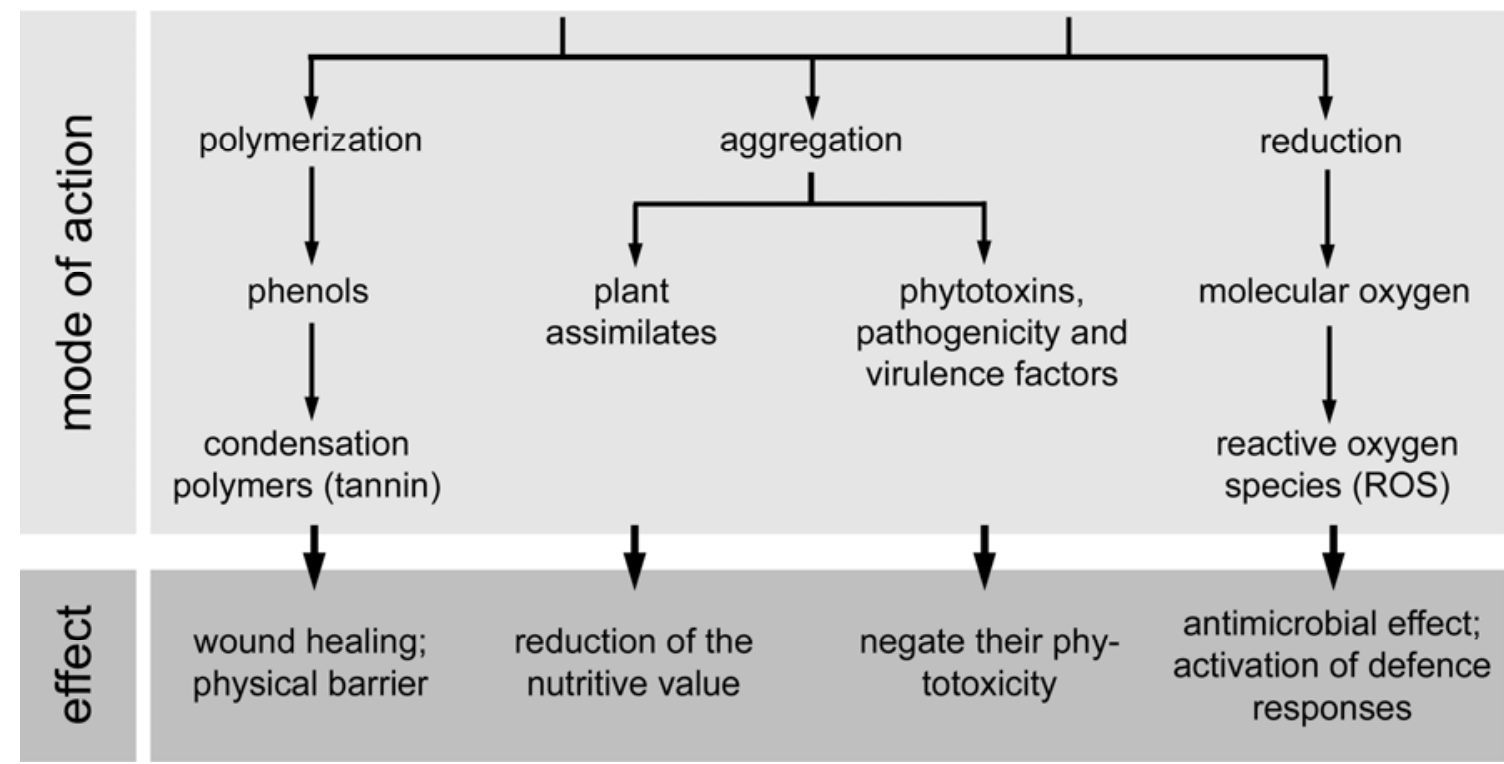

Fig. 7. Overview of potential roles of quinones and semiquinones generated by polyphenol oxidases (PPO) in protecting plants against pathogens. Secondary, nonenzymatic reactions of quinones and semiquinones may play a role in plant defense against pathogens. Polymerization with phenols can result in a large number of condensation polymers that can seal off the site of infection or wounding and build up a physical barrier against the entry of pathogens. Reactions with other proteins can reduce their bioavailability to pathogens, while reactions with exoenzymes produced by the pathogen (e.g., phytotoxins, pathogenicity factors, or virulence factors) can negate their phytotoxicity. Also, quinones and semiquinones are able to carry out the single-electron reduction of molecular oxygen to superoxide anion radical, which may, in turn, give rise to other reactive oxygen species (ROS). ROS can have direct antimicrobial effects and activate a number of plant defense responses. 
To remove DNA contaminations, a DNaseI treatment was performed with the RQ1RNAse-Free DNAseI (Promega, Mannheim, Germany) following the manufacturer's instructions. RNA was extracted with 0.9 volume of phenol/chloroform (1:1) and was centrifuged at $8,000 \times g$ for $5 \mathrm{~min}$, followed by a second extraction with 1 volume of chloroform/isoamylalcohol (24:1). After centrifugation at $8,000 \times g$ for $5 \mathrm{~min}, 0.1$ volume of $3 \mathrm{M} \mathrm{Na}$-acetate ( $\mathrm{pH} 4.8$ ) was added to the supernatant and RNA was precipitated with 2.5 volumes of $\mathrm{EtOH}$ at $-80^{\circ} \mathrm{C}$ for $35 \mathrm{~min}$. After centrifugation at $8,000 \times g$ and $4^{\circ} \mathrm{C}$ for $20 \mathrm{~min}$, the RNA pellet was washed twice with $70 \%$ EtOH. Total RNA pellets were dissolved in $50 \mu \mathrm{l}$ of RNase-free water, and quantification was done by spectrophotometry and gel electrophoresis.

An aliquot of $1 \mu \mathrm{g}$ of total RNA of each sample was reversely transcribed using M-MLV reverse transcriptase (Promega) and Oligo $\left(\mathrm{dT}_{18}\right)$ primer, following the manufacturer's instructions. PCR amplification was performed using MangoTaq DNA polymerase (Bioline, Luckenwalde, Germany) and gene-specific primers: PPO1_fw (5'-GAC ATT CCA GCA GGT GGT ATA GT-3') and PPO1_rev (5'-TGG GTC ATT GAT TAA TTT GCC AC-3') for ppo- 1 ; PPO2_fw (5'-GAC TTA CCC CAA GGT GCT GTA GC-3') and PPO2_rev (5'-TCA GTG TTC ATC GGC TCG AGC-3') for ppo-2; PPO3_fw (5'-ACC TGC CAA AAG GTG CTA TAC G-3') and PPO3_rev (5'-AGC TTG ATA GCC TTA TTG AAT TTG-3') for ppo-3; PPO4_fw (5'-AAC AGC GCC GAC GCT GTA AGA GG-3') and PPO4_rev (5'-CAA TGA ATC TTA CCT TGT TGC TTC-3') for ppo-4; PPO5_fw (5'-ACC TTC CCC GAA GGT GTT GCC A-3') and PPO5_rev (5'-CAA TGA ACA CTA GCT TGT TGC ATA-3') for ppo-5; GAP_fw (5'-CTT CAG AGA GAT GAT GTT GAG C-3') and GAP_rev (5'-CTT CCA CCT CTC CAG TCC TT-3') for T. officinale gap and $A$. thaliana gapc-2; GAP-Pst_fw (5'-CGC CAT TCG CAA CCC G-3') and GAP-Pst_rev (5'-GTC GTA CCA CGA GAG CAC-3') for P. syringae pv. tomato gap-1; ACT-Bc_fw (5'-AAG TGT GAT GTT GAT GTC C-3') and ACT-Bc_rev (5'-CTG TTG GAA AGT AGA CAA AG-3') for $B$. cinerea actA. The fragments were separated by electrophoresis using $1.5 \%$ agarose gels followed by ethidium bromide staining and UV light visualization.

\section{ppo-2 RNAi constructs, construct}

for heterologous expression, and ppo-2:GUS constructs.

For the two RNAi constructs of the ppo-2 gene, a 846-bp PCR fragment was amplified using primers RNAi_fw-I (5'-TTT GGT ACC GGC ATC TCT TGC ACC ATC-3') and RNAi_rev-I (5'-TTT GCG GCC GCT TGC TGA GAT TCT CAT CTT C-3'), and a 141-bp PCR fragment was amplified using primers RNAi_fw-V (5'-TTT GGT ACC ATC CAT TGG CCT TTG CAG-3') and RNAi_rev-V (5'-TTT GCG GCC GCG TGG TGG AAG TTT GAA GTC-3'). Each PCR fragment was inserted into the Gateway vector pENTR4 (Invitrogen, Karlsruhe, Germany) and then transferred to the destination plasmid pFGC5941 (ChromDB database) containing the chalcone synthase intron to obtain pFGC5941-RNAi-I and pFGC5941-RNAi-V, respectively.

For the heterologous expression of the ppo-2 gene in $A$. thaliana, the whole-gene sequence was amplified using genespecific primers PPO-2FL_fw (5'-TTT GTC GAC ATG GCA TCT CTT GCA CCA TC-3') and PPO-2FL_rev (5'-TTT GCT AGC CCA GTC AAT CCT CAT ACT CG-3'). The PCR fragment, under the control of the CaMV $35 \mathrm{~S}$ promoter, was inserted into the pCambia2300 vector (Cambia, Canberra Australia) to obtain pCambiaP35S:ppo-2.

For the construction of ppo-2:GUS, the promoter sequences were amplified using specific primers $\left(5^{\prime}\right.$-TTT CTG CAG ATG CCT GAT TGA TTC AAG TG-3' and 5'-TTT CTC GAG ATT CTT AGT TTA AGG GTG AG-3'), and then, the uidA (gusA) gene was placed under the control of ppo-2I and ppo-2II and was inserted into the pLab121 vector (based on pFGC5941) to obtain pLab121ppo-2:GUS. The integrity of all constructs was verified by sequencing.

\section{Plant transformation.}

T. officinale was transformed by Agrobacterium tumefaciensmediated leaf-disk infection. Agrobacterium tumefaciens LBA4404 (pAL4409) (Hoekema et al. 1983), carrying pFGC5941-RNAi-I/V or pLab121ppo-2:GUS, was cultured in $200 \mathrm{ml}$ of induction broth $(5 \mathrm{~g}$ of sucrose, $5 \mathrm{~g}$ of peptone, $5 \mathrm{~g}$ of casein hydrolysate, and $1 \mathrm{~g}$ of yeast extract per liter, $10 \mathrm{mM}$ MES, $2 \mathrm{mM} \mathrm{MgSO}_{4}$, pH 5.6) containing $200 \mu \mathrm{M}$ acetosyringone and $50 \mathrm{mg}$ of kanamycin, $100 \mathrm{mg}$ of rifampicin, and 300 $\mathrm{mg}$ of streptomycin per liter. Bacteria were cultured at $28^{\circ} \mathrm{C}$ to the end of the log phase and then centrifuged, and the pellet was resuspended to a final $\mathrm{OD}_{600}$ of approximately 1.0 in coculture medium (4.4 g of Murashige-Skoog salt solution, including vitamins, per liter, $10 \mathrm{mM}$ MES, $20 \mathrm{~g}$ of glucose per liter, pH 5.6) supplemented with $200 \mu \mathrm{M}$ acetosyringone. Leaf disks (approximately $1 \mathrm{~cm}^{2}$ ) were punched from the leaves of 6-to-10-week-old T. officinale plants that had been grown under sterile conditions on solid medium (2.2 g of MurashigeSkoog salt solution, $10 \mathrm{~g}$ of glucose, and $8 \mathrm{~g}$ of agar per liter, $\mathrm{pH}$ 5.8) and were inoculated in the coculture medium with Agrobacterium tumefaciens for $30 \mathrm{~min}$. The leaf disks were then placed on filter paper at $26^{\circ} \mathrm{C}$ for 14 to $20 \mathrm{~h}$. To induce regeneration, leaf disks were placed on regeneration medium (4.4 g of Murashige-Skoog salt solution, including vitamins, $18 \mathrm{~g}$ of glucose, and $8.3 \mathrm{~g}$ of agar per liter, $\mathrm{pH}$ 5.8) supplemented with $1 \mathrm{mg}$ of 6-benzyladenine and $0.2 \mathrm{mg}$ of naphthalenacetic acid per liter for callus and shoot induction. The elongation of shoots was maintained by the addition of $2 \mathrm{mg}$ of zeatin, $20 \mu \mathrm{g}$ of naphthalenacetic acid, and $20 \mu \mathrm{g}$ of gibberellic acid $\mathrm{GA}_{3}$ per liter. Rooting was induced on regeneration medium without hormones, whereas all regeneration media contained $3 \mathrm{mg}$ of phosphinothricin per liter for selection.

A. thaliana was transformed by floral dip as described by Clough and Bent (1998). To obtain more floral buds per plant, inflorescences were clipped after most plants had formed primary bolts. Plants were dipped when most secondary inflorescences were about $10 \mathrm{~cm}$ tall. Agrobacterium tumefaciens EHA105 (pTiBo542) (Hood et al. 1993), carrying pCambiaP35S:ppo-2, was cultured in $200 \mathrm{ml}$ of broth $(5 \mathrm{~g}$ of sucrose, $5 \mathrm{~g}$ of peptone, $5 \mathrm{~g}$ of casein hydrolysate, and $1 \mathrm{~g}$ of yeast extract per liter and $2 \mathrm{mM} \mathrm{MgSO}_{4}, \mathrm{pH}$ 7) containing $50 \mathrm{mg}$ of kanamycin and $100 \mathrm{mg}$ of rifampicin per liter. Bacteria were cultured at $28^{\circ} \mathrm{C}$ to the end of the $\log$ phase, were centrifuged, and were then resuspended in 5\% sucrose and $0.02 \%$ Silwet Gold (Spiess Urania) to a final $\mathrm{OD}_{600}$ of approximately 0.8 prior to use. For floral dip, plants were dipped into this inoculum for $30 \mathrm{~s}$. Plants were placed in a plastic tray and were covered with a clear plastic bag to maintain humidity for 2 days. After 4 to 6 weeks, the seeds were harvested and surface-sterilized. To select for transformed plants, sterilized seeds were suspended in $0.1 \%$ sterile agarose, were plated on kanamycin selection plates (2.2 g of Murashige-Skoog salt solution including vitamins, $10 \mathrm{~g}$ of sucrose, $9 \mathrm{~g}$ of agar, $50 \mathrm{mg}$ of kanamycin per liter), were cold-treated at $4^{\circ} \mathrm{C}$ for 2 days, and were then grown in a controlled environment for 7 to 10 days (16-h days at $20^{\circ} \mathrm{C}$ and 8 -h nights at $18^{\circ} \mathrm{C}$ ) before transfer to soil.

\section{Quantitative real-time PCR analyses.}

For quantitative real-time PCR analysis of ppo-2 gene expression in knockdown plants, leaves from 6-to-8-week-old $T$. officinale plants were inoculated with $B$. cinerea by spraying a conidia suspension $\left(10^{6}\right.$ conidia per milliliter of B5 medium) 
to the surface of dandelion leaves. Control leaves were treated with B5 medium only. The leaves were harvested after $48 \mathrm{~h}$ and were immediately frozen in liquid nitrogen. Total RNA and cDNA was extracted as described before. Real-time PCR tests were conducted in an iCycler (Bio-Rad, Hercules CA, U.S.A.), using the iQ SYBR Green Supermix (Bio-Rad). For each reaction, $0.25 \mu \mathrm{l}$ of cDNA, $12.5 \mu \mathrm{l}$ of reaction mix, and 5 $\mu \mathrm{l}$ of equimolar mixes of primers $\left(20 \mathrm{pmol} \mu \mathrm{l}^{-1}\right)$ in a total volume of $25 \mu \mathrm{l}$ were used. PCR reactions were performed for 45 cycles according to the following temperature scheme: $10 \mathrm{~s}$ at $95^{\circ} \mathrm{C}, 30 \mathrm{~s}$ at $62^{\circ} \mathrm{C}$. After amplification, melting-curve analyses were performed to exclude artefactual amplifications. Following determination of cycle threshold values, the normalization of ppo-2 expression was calculated, using gap as constitutive control. The ratio of ppo-2 expression was calculated using the delta-delta method (ratio $=2^{-\Delta \Delta \mathrm{CP}}$ ) (Livak and Schmittgen 2001). For real-time PCR, the following primers were used: PPO2_fwRT (5'-TTA CCC CAA GGT GCT GTA GC-3') and PPO2_revRT (5'-GAG GGT GGT GGA AGT TTG AAG-3') for ppo-2, and GAP_fwRT (5'-CCG TCA ACG ATC CGT TTA TCA C-3') and GAP_revRT (5'-GCT TCC ATT GTC CAT GAA CAG TG-3') for gap.

\section{Histochemical GUS-staining and localization of $B$. cinerea in infected plants.}

Histochemical assays were performed using X-gluc (5bromo-4-chloro-3-indolyl- $\beta$-D-glucuronide) (Biosynth, Naperville IL, U.S.A.) as a substrate (Jefferson 1987). Inoculated or control leaves were placed in the substrate solution $(0.5 \mathrm{mg}$ of $\mathrm{X}$-gluc per liter in $50 \mathrm{mM} \mathrm{Na}-\mathrm{P}_{\mathrm{i}}$ buffer [pH 7.0], $5 \mathrm{mM}$ $\mathrm{K}_{3} \mathrm{Fe}(\mathrm{CN})_{6}, 10 \mathrm{mM}$ EDTA, and $0.01 \%$ Triton X-100) and were vacuum-infiltrated for $40 \mathrm{~s}$. The GUS enzymatic reaction was then allowed to proceed at $37^{\circ} \mathrm{C}$ overnight. The leaves were washed three times in $50 \mathrm{mM} \mathrm{Na}-\mathrm{P}_{\mathrm{i}}$ buffer $(\mathrm{pH} 7.0)$ for $5 \mathrm{~min}$, were incubated in fixation solution $(20 \% \mathrm{EtOH}, 5 \%$ acetic acid, 5\% formaldehyde) for $30 \mathrm{~min}$, and were then destained in $20 \%$ chloroform in EtOH. Leaves were stored in $75 \% \mathrm{EtOH}$ until use. $B$. cinerea was visualized in infected tissues using calcofluor white, which binds to chitin in the fungal cell wall. The inoculated leaves were placed in staining solution $(0.05 \%$ fluorescent brightener in $100 \mathrm{mM} \mathrm{Na}-\mathrm{P}_{\mathrm{i}}$ buffer, $\mathrm{pH}$ 7.0) for 20 min and were then washed in the same buffer. Samples were observed with an Olympus BX40 microscope (Olympus, Hamburg, Germany).

\section{Growth of $P$. syringae pv. tomato in transgenic $T$. officinale plants.}

To evaluate the effect of PPO-2 in the knockdown plants, 6to-8-week-old T. officinale plants (WT, I-1, I-2, and V-2) were inoculated by dipping the leaves into a bacterial suspension containing $2 \times 10^{6} \mathrm{CFU}$ of $P$. syringae pv. tomato per milliliter, $5 \mathrm{mM} \mathrm{MgCl}$, and $0.05 \%$ Silwet Gold (Spiess Urania) for $30 \mathrm{~s}$. Inoculated plants were incubated under a transparent plastic box to retain high humidity. Bacterial growth was assayed from leaf extracts prepared from four leaf disks per plant $(5 \mathrm{~mm}$ disk diameter) in $10 \mathrm{mM} \mathrm{MgCl}$. The bacterial population was determined by plating serial dilutions with triplicates on NYG agar plates supplemented with $100 \mathrm{mg}$ of rifampicin and 50 $\mathrm{mg}$ of kanamycin per liter. The CFU were counted after incubation at $28^{\circ} \mathrm{C}$ for 2 days and were normalized to CFU per square centimeter.

\section{A. thaliana leaf extract.}

A. thaliana leaves from transgenic and control plants were ground to a fine powder in liquid nitrogen and were subsequently homogenized in $2 \mathrm{ml}$ of Tris-maleate buffer $(50 \mathrm{mM}$, $\mathrm{pH}$ 6). The extract was centrifuged at $12,000 \times g$ at $4^{\circ} \mathrm{C}$ for
$15 \mathrm{~min}$, and the supernatant was transferred to a fresh tube. The protein concentration of the extract was quantified by the method of Bradford (1976), using bovine serum albumin as a standard.

\section{PPO activity.}

PPO activity was measured spectrophotometrically by following the conversion of dopamine (3,4-dihydroxyphenethylamine) (Sigma-Aldrich, München, Germany) to dopaminechrome at $480 \mathrm{~nm}\left(\varepsilon=3,300 \mathrm{M}^{-1} \mathrm{~cm}^{-1}\right.$; Rodriguez-Lopez 1993), using a microplate reader (Molecular Devices, Sunnyvale CA, U.S.A.). For each measurement, $10 \mu \mathrm{l}$ of leaf extracts (protein content $=1 \mathrm{mg} \mathrm{ml}^{-1}$ ) from transgenic and wild-type A. thaliana plants were added to $1 \mathrm{mM}$ substrate dissolved in $50 \mathrm{mM}$ Tris-maleate buffer $(\mathrm{pH}$ 6) to a total volume of $67 \mu 1$.

For heat inactivation, leaf extracts were heated to $100^{\circ} \mathrm{C}$ for $10 \mathrm{~min}$ before measuring PPO activity or using for antibacterial tests.

\section{Antibacterial test in microtiter plates.}

Sterile, flat-bottomed 96-well plates (Greiner Bio-One $\mathrm{GmbH}$, Frickenhausen, Germany) were filled with $150 \mu \mathrm{l}$ of minimal medium (13 mM potassium phosphate, $17 \mathrm{mM}$ sodium chloride, $30 \mathrm{mM}$ ammonium sulfate, $2.8 \mathrm{mM}$ magnesium sulfate, $10 \mathrm{mM}$ fructose, $\mathrm{pH} 5.5$ ) in each well. The bacterial suspension $(10 \mu \mathrm{l})$ containing $P$. syringae pv. tomato at $10^{8} \mathrm{CFU}$ $\mathrm{ml}^{-1}$ or $10 \mu \mathrm{l}$ of buffer (blanks) were added. Then, untreated or heat-inactivated leaf extracts (protein content $=1 \mathrm{mg} \mathrm{ml}^{-1}$ ) from transgenic and wild-type $A$. thaliana plants $(30 \mu \mathrm{l})$ were transferred into the wells. Each well was then filled up to the end volume of $200 \mu \mathrm{l}$, either with $10 \mu \mathrm{l}$ of $20 \mathrm{mM}$ dopamine or with $10 \mu \mathrm{l}$ of $50 \mathrm{mM}$ Tris-maleate buffer (pH 6). The effect of the leaf extracts was tested in triplicates. The plates were incubated for $7 \mathrm{~h}$ at $28^{\circ} \mathrm{C}$ and $200 \mathrm{rpm}$ (Multitron2; Infors AG, Bottmingen, Switzerland). For monitoring bacterial growth, $198 \mu \mathrm{l}$ of fresh minimal medium supplemented with $0.05 \%$ peptone was filled in a second microtiter plate and $2 \mu \mathrm{l}$ of samples from the first plate were used for inoculation. Growth was assayed for $16 \mathrm{~h}$ at 10-min intervals, by measuring the $\mathrm{OD}_{600}$. The microtiter plates were shaken between reads for $20 \mathrm{~s}$.

\section{ACKNOWLEDGEMENTS}

The authors thank F. Foucu and J. Boike for the identification of the first five PPO fragments. The technical assistance of U. Fassin and E. Aguado is acknowledged. This work was supported in part by a scholarship to C. Richter given by the Westphalian Wilhelms-University of Münster, Germany, by Bundesministerium für Bildung und Forschung grant FKZ 0313712 to D. Prüfer, and by a scholarship to M. Dirks given by the Deutsche Bundesstiftung Umwelt.

\section{LITERATURE CITED}

Antoniw, J. F., Ritter, C. E., Pierpoint, W. S., and van Loon, L. C. 1980. Comparison of three pathogenesis-related proteins from plants of two cultivars of tobacco infected with TMV. J. Gen. Virol. 47:79-87.

Bashan, Y., Okon, Y., and Henis, Y. 1987. Peroxidase, polyphenoloxidase, and phenols in relation to resistance against Pseudomonas syringae pv. tomato in tomato plants. Can. J. Bot. 65:366-372.

Bolwell, G. P. 1999. Role of active oxygen species and NO in plant defence responses. Curr. Opin. Plant Biol. 2:287-294.

Bradford, M. M. 1976. A rapid and sensitive method for the quantification of microgram quantities of protein utilizing the principle of protein-dye binding. Anal. Biochem. 72:248-254.

Chen, G. Y.-J., Jin, S., and Goodwin, P. H. 2000. An improved method for the isolation of total RNA from Malva pusilla tissues infected with Colletotrichum gloeosporioides. J. Phytopathol. 148:57-60.

Clough, S., and Bent, A. F. 1998. Floral dip: A simplified method for Agrobacterium-mediated transformation of Arabidopsis thaliana. Plant J. 16:735-743.

Coetzer, C., Corsini, D., Love, S., Pavek, J., and Tumer, N. 2001. Control 
of enzymatic browning in potato (Solanum tuberosum L.) by sense and antisense RNA from tomato polyphenol oxidase. J. Agric. Food Chem. 49:652-657.

Doyle, J. J., and Doyle, J. L. 1990. Isolation of plant DNA from fresh tissue. Focus 12:13-15.

Elad, Y., Williamson, B., Tudzynski, P., and Delen, N. 2004. Botrytis: Biology, Pathology and Control. Kluwer Academic Publishers, Dordrecht, The Netherlands.

Emanuelsson, O., Nielsen, H., and von Heijne, G. 1999. ChloroP, a neura network-based method for predicting chloroplast transit peptides and their cleavage sites. Protein Sci. 8:978-984.

Escudero, N. L., De Arellano, M. L., Fernández, S., Albarracín, G., and Mucciarelli, S. 2003. Taraxacum officinale as a food source. Plants Food Hum. Nutr. 58:1-10.

Felton, G. W., Donato, K., Del Vecchio, R. J., and Duffey, S. S. 1989. Activation of plant foliar oxidases by insect feeding reduces nutritive quality of foliage for noctuid herbivores. J. Chem. Ecol. 15:2667-2694.

Felton, G. W., Donato, K. K., Broadway, R. M., and Duffey, S. S. 1992. Impact of oxidized plant phenolics on the nutritional quality of dietary protein to a noctuid herbivore, Spodoptera exigua. J. Insect Physiol. 38:277-285.

Ferreira, R. B., Monteiro, S., Freitas, R., Santos, C. N., Chen, Z., Batista L. M., Duarte, J., Borges, A., and Teixeira, A. R. 2007. The role of plant defence proteins in fungal pathogenesis. Mol. Plant Pathol. 8:677-700.

Guilley, H., Dudley, R. K., Jonard, G., Balazs, E., and Richards, K. E. 1982. Transcription of Cauliflower mosaic virus DNA: Detection of promoter sequences, and characterization of transcripts. Cell 30:763773.

Hammond-Kosack, K. E., and Jones, J. D. G. 1996. Resistance genedependent plant defense responses. Plant Cell 8:1773-1791.

Hoekema, A., Hirsch, P. R., Hooykaas, P. J. J., and Schilperoort, R. A. 1983. A binary plant vector strategy based on separation on vir- and T-region of the Agrobacterium tumefaciens Ti-plasmid. Nature 303:179-180.

Hood, E. E., Gelvin, S. B., Melchers, S., and Hoekema, A. 1993. New Agrobacterium helper plasmid for gene transfer to plants (EHA 105). Transgenic Res. 2:208-218.

Jefferson, R. A. 1987. Assaying chimeric genes in plants: The GUS gene fusion system. Plant Mol. Biol. Rep. 5:387-405.

Lamb, C., and Dixon, R. A. 1997. The oxidative burst in plant disease resistance. Annu. Rev. Plant Physiol. Plant Mol. Biol. 48:251-275.

Levine, A., Pennell, R. I., Alvarez, M. E., Palmer, R., and Lamb, C. 1996. Calcium-mediated apoptosis in a plant hypersensitive disease resistance response. Curr. Biol. 6:427-437.

Li, L., and Steffens, J. C. 2002. Overexpression of polyphenol oxidase in transgenic tomato plants results in enhanced bacterial disease resistance. Planta 215:239-247.

Livak, K. J., and Schmittgen, T. D. 2001. Analysis of relative gene expression data using real-time quantitative PCR and the $2^{\wedge}[$-delta delta(CT)] method. Methods 25:402-408.

Mayer, A. M. 1987. Polyphenol oxidase in plant-recent progress. Phytochemistry 26:11-20.

Mayer, A. M. 2006. Polyphenol oxidases in plants and fungi: Going places? A review. Phytochemistry 67:2318-2331.

Mayer, A. M., and Harel, E. 1979. Polyphenol oxidases in plants. Phytochemistry 31:193-215.

Murata, M., Haruta, M., Murai, N., Tanikawa, N., Nishimura, M., Homma S., and Itoh, Y. 2000. Transgenic apple (Malus domestica) shoot showing low browning potential. J. Agric. Food Chem. 48:5243-5248.

Murata, M., Nishimura, M., Murai, N., Haruta, M., Homma, S., and Itoh, Y. 2001. A transgenic apple callus showing reduced polyphenol oxidase activity and low browning potential. Biosci. Biotechnol. Biochem. 65:383-388

Niranjan Raj, S., Sarosh, B. R., and Shetty, H. S., 2006. Induction and accumulation of polyphenol oxidase activities as implicated in development of resistance against pearl millet downy mildew disease. Funct. Plant Biol. 33:563-571.

Pourcel, L., Routaboul, J.-M., Cheynier, V., Lepiniec, L., Debeaujon, I., 2007. Flavonoid oxidation in plants: From biochemical properties to physiological functions. Trends Plant Sci. 12:29-36.
Quidde, T., Büttner, P., and Tudzynski, P. 1999. Evidence for 3 different specific saponin-detoxyfying activities in Botrytis cinerea and cloning and functional analysis of a gene coding for a putative avenacinase. Eur. J. Plant Pathol. 105:273-283.

Richards, A. J. 1973. The origin of Taraxacum agamospecies. Bot. J. Linn. Soc. 66:189-211.

Roby, D., Broglie, K., Cressman, R., Biddle, P., Chet, I., and Broglie, R. 1990. Activation of a bean chitinase promoter in transgenic tobacco plants by phytopathogenic fungi. Plant Cell 2:999-1007.

Rodriguez-Lopez, J. N., Ros, J. R., Varón, R., Garcia-Cánovas, F. 1993 Oxygen Michaelis constants for tyrosinase. Biochem. J. 293:859-866.

Stewart-Wade, S. M., Neumann, S., Collins, L. L., and Boland, G. J. 2002. The biology of Canadian weeds. 117. Taraxacum officinale G. H. Weber ex Wiggers. Can. J. Plant Sci. 82:825-853.

Sullivan, M. L., Hatfield, R. D., Thoma, S. L., and Samac, D. A. 2004. Cloning and characterization of red clover polyphenol oxidase cDNAs and expressing of active protein in Escherichia coli and transgenic alfalfa. Plant Physiol. 136:3234-3244.

Thipyapong, P., and Steffens, J. C. 1997. Tomato polyphenol oxidase. Plant Physiol. 115:409-418.

Thipyapong, P., Hunt, M. D., and Steffens, J.C. 2004a. Antisense downregulation of polyphenol oxidase results in enhanced disease susceptibility. Planta 220:105-117.

Thipyapong, P., Melkonian, J., Wolfe, D. W., and Steffens, J. C. 2004b. Suppression of polyphenol oxidases increases stress tolerance in tomato. Plant Sci. 167:693-703.

Thipyapong, P., Stout, M. J., and Attajarusit, J. 2007. Functional analysis of polyphenol oxidase by antisense/sense technology. Molecules 12:1569-1595.

van Dijk, P. J. 2003. Ecological and evolutionary opportunities of apomixes: Insights from Taraxacum and Chondrilla. Philos. T. R. Soc. Lond. 358:1113-1121.

van Dijk, P. J., and Bakx-Schotman, J. M. T. 2004. Formation of unreduced megaspores (diplospoy) in apomictic dandelions (Taraxacum officinale, s.l.) is controlled by a sex-specific dominant locus. Genetics 166:483-492.

van Loon, L. C., Pierpoint, W. S., Boller, T., and Conejero, V. 1994 Recommendations for naming plant pathogenesis-related proteins. Plant Mol. Biol. Rep. 12:245-264.

van Loon, L. C., Rep, M., and Pieterse, C. M. 2006. Significance of inducible defense-related proteins in infected plants. Annu. Rev. Phytopathol. 44:135-162.

Vaughn, K. C., Lax, A. R., and Duke, S. O. 1988. Polyphenol oxidase: The chloroplast oxidase with no established function. Phys. Plant 72:659665.

Wahler, D., Schulze Gronover, C., Richter, C., Foucu, F.; Twyman, R. M., Moerschbacher, B. M., Fischer, R., Muth, J., Prüfer, D. 2009. Polyphenoloxidase silencing affects latex coagulation in Taraxacum species. Plant Physiol. 151:334-346.

Walker, J. R. L., and Ferrar, P. H. 1998. Diphenol oxidases, enzyme-catalysed browning and plant disease resistance. Biotechnol. Genet. Eng. Rev. 15:457-498.

Wang, J., and Constabel, C. P. 2004. Polyphenol oxidase overexpression in transgenic Populus enhances resistance to herbivory by forest tent caterpillar (Malacosoma disstria). Planta 220:87-96.

Williams, C. A., Goldstone, F., Greenham, J. 1996. Flavonoids, cinnamic acids and coumarins from the different tissues and medicinal preparations of Taraxacum officinale. Phytochemisry 42:121-127.

Wu, Y.-L., Pan, L.-P., Yu, S.-L., Li, H.-H. 2010. Cloning, microbial expression and structure-activity relationship of polyphenol oxidases from Camellia sinensis. J. Biotechnol. 145:66-72.

Yoruk, R., and Marshall, M. R. 2003. Physicochemical properties and function of plant polyphenol oxidase: A review. J. Food Biochem. 27:361-422.

\section{AUTHOR-RECOMMENDED INTERNET RESOURCE}

ChromDB, the chromatin database: www.chromDB.org 